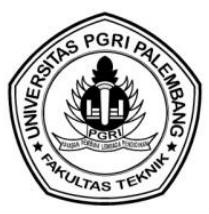

\title{
STUDI ANGLE OF REPOSE MUD VOLCANO DI DESA NAPAN PULAU TIMOR
}

\author{
Mauritius I. R. Naikofi ${ }^{1 *}$, Budijanto Widjaja ${ }^{2}$ dan Paulus P. Rahardjo ${ }^{3}$ \\ ${ }^{1}$ Program Studi Teknik Sipil, Fakultas Teknik, Universitas Katolik Wydia Mandira Kupang \\ ${ }^{2,3}$ Jurusan Teknik Sipil, Fakultas Teknik, Universitas Katolik Parahyangan \\ ${ }^{*}$ Corresponding author, e-mail : mauritiusnaikofi@yahoo.co.id
}

\begin{abstract}
ABSTRAK
Semburan lumpur vulkanik (Mud Volcano) di pulau Timor (Desa Napan) merupakan aliran lumpur bertemperatur rendah membentuk gunung-gunung lumpur yang berhenti pada ketinggian tertentu dan tumbuh lagi pada titik yang lain. Aliran lumpur alamiah ini membawa massa material berupa tanah dan material berbutir yang terus menerus tanpa harus dipengaruhi oleh adanya aktivitas gunung berapi atau kondisi curah hujan yang tinggi. Letak semburan mud volcano yang sangat dekat dengan permukiman penduduk, memungkinkan terjadinya peristiwa bencana yang akan mengacam bangunan dan kehidupan penduduk dan berdampak juga pada area pertanian. Penelitian ini dilakukan untuk melengkapi penelitian terdahulu oleh Naikofi, dkk. (2017) mengenai sifat aliran lumpur (Mudflow) mud volcano desa Napan. Hasil penelitian angle of repose yang dibentuk oleh gunung lumpur vulkanik tersebut menunjukkan bahwa pada saat variasi kadar air mendekati atau sama dengan batas cair, yaitu pada kadar air sama dengan $27.55 \%$ diperoleh angle of repose sebesar $28.71^{\circ}$. Penelitian ini dilakukan untuk melengkapi data terpublikasi terdahulu oleh Naikofi, dkk. (2017) mengenai sifat aliran lumpur (Mudflow) mud volcano desa Napan. Informasi ini diharapkan hasilnya mendekati studi lumpur vulkanik yang dilakukan oleh peneliti-peneliti terdahulu.
\end{abstract}

Kata Kunci : Lumpur vulkanik, gunung lumpur, angle of repose

\section{PENDAHULUAN}

Bidang geoteknik menggolongkan aliran lumpur sebagai satu tipe pergerakan massa tanah (longsoran) dengan material yang umumnya berupa tanah berbutir halus dan memiliki kecepatan transportasi yang tinggi (Widjaja dan Pratama 2015). Salah satu penyebab terjadinya mudflow adalah terjadinya perubahan kadar air pada tanah. Menurut Widjaja and Setiabudi (2014), mudflow terjadi karena kondisi kadar air sama atau lebih dari batas cair. Dengan pengertian lain mudflow terjadi pada kondisi viscous liquit atau indeks kecairan lebih dari 1 (Widjaja dkk.2014). Menurut Hurger et al (2001), mudflow didefinisikan sebagai suatu pergerakan massa tanah dengan material yang umumnya berbutir halus, memiliki kecepatan transportasi yang tinggi melebihi $5 \mathrm{~cm} / \mathrm{s}$. Mudflow tidak selalu tersusun dari butiran halus tapi bisa juga terdiri dari campuran batuan kecil atau kerikil (Widjaja,dkk. 2014; Fang and Daniels 2006).

Mud volcano merupakan suatu gunung api lumpur yang membentuk suatu kerucut tanah liat dan lumpur berukuran kecil. Mekanisme terjadinya lumpur vulkanik dalam Herawati (2007) dijelaskan bahwa semburan lumpur vulkanik dapat terjadi karena adanya liquifaction (pencairan) atau seperti agar-agar yg dihentakkan secara mendadak sehingga menyembur keluar. Pada kondisi stabil mobile shale (mobile clay) dapat menyerupai tanah lempung yang sering dilihat dipermukaan bumi dengan wujud sangat liat. Namun ketika 
kondisi dinamis karena mengalir maka percampuran dengan air bawah tanah menjadikan lempung ini seperti bubur. Lumpur vulkanik ini bisa mengalir keluar melalui crack (patahan) yang sudah ada dapat juga melalui pinggiran sumur dengan membentuk crack/fracture yang baru.

Aliran mud volcano yang terjadi di pulau Timor (Desa Napan) merupakan semburan lumpur vulkanik dengan temperatur rendah (dingin) yang terjadi secara alamiah sepanjang waktu tanpa adanya aktivitas gunung berapi maupun aktivitas lainnya. Fenomena ini menjadikan area munculnya gunung lumpur tersebut bertambah banyak dan bertambah luas sehingga penelitian ini bertujuan untuk mengetahui besarnya sudut henti yang dibentuk oleh aliran lumpur vulkanik dan melengkapi penelitian terdahulu mengenai sifat aliran lumpul vulkanik Desa Napan Pulau Timor oleh Naikofi dkk. (2017) tersebut melalui pengujian laboratorium dan metode trigonometri.

\section{TINJAUAN PUSTAKA}

Menurut Widjaja dan Pratama (2015) Aliran lumpur (mudflow) merupakan perpindahan material tanah berupa aliran lumpur bercampur butiran kasar maupun halus dalam kondisi jenuh air. Dalam bidang geoteknik, aliran lumpur merupakan salah satu tipe pergerakan massa tanah (longsoran) dengan material yang umumnya berupa tanah berbutir halus dan memiliki kecepatan transportasi yang tinggi (Widjaja dan Pratama 2015). Salah satu penyebab terjadinya mudflow adalah terjadinya perubahan kadar air pada tanah. Menurut Widjaja dan Setiabudi (2014), mudflow terjadi karena kondisi kadar air sama atau lebih dari batas cair. Dengan pengertian lain mudflow terjadi pada kondisi viscous liquit atau Liquidity Index (LI) atau indeks kecairan lebih dari 1 (LI $\geq 1$ ).

Awang (2001), Mendefinisikan mud volcano sebagai endapan lumpur yang mempunyai density lebih ringan dari batuan sekitarnya, mobilitas tinggi, naik kepermukaan melalui bidang lemah sebagai konduit baik berupa sesar (mendatar maupun tegak) serta rekahan-rekahan dan membentuk kerucut seperti gunung api dengan ketinggian berkisar dari 17-30 meter. Komposisi mud volcano ini terdiri atas semua material yang dikeluarkan dari perut bumi baik berupa massa padat, plastis, cair, dan gas. Massa padat berupa bebatuan dan garam, sedangkan massa plastis berupa bubur lempung. Sebaliknya massa cair dapat berupa air (air tanah, air magmatik/vulkanik dan air laut) sedangkan massa gas berupa gas metan, hidrat dan gas belerang.

Definisi lain, mud volcano merupakan suatu gunung api lumpur yang membentuk suatu kerucut tanah liat dan lumpur berukuran kecil, yang umumnya berkisar 1-2 meter tingginya. Gunung api lumpur kecil ini terbentuk dari campuran air panas dan sedimen halus (tanah liat dan lumpur dimana terdapat aliran perlahan dari suatu lubang seperti arus arus lahar cair; atau menyembur ke udara seperti suatu aliran mancur lahar yang melepaskan air mendidih dan gas vulkanis (Awad, 2006; Herawati, 2007).

Mud volcano dapat dibagi 2 jenis utama, yaitu mud volcano yang berasosiasi dengan gunung api dan mud volcano yang tidak ada hubungan sama sekali dengan gunung api. Mud volcano tipe pertama dicirikan keberadaannya berdekatan dengan gunung api aktif. Umumnya, mud volcano jenis ini bersuhu tinggi, mengeluarkan uap air dengan jumlah besar dan tidak hadirnya gas hidrokarbon. Mud volcano tipe kedua adalah jenis yang tidak 
ada kaitan dengan gunung api. Dengan kata lain, jenis ini meletus secara independen tanpa terkait dengan gunung api. Mud volcano ini dicirikan dengan air letusan yang relatif bersuhu rendah/dingin dan mengandung material hidrokarbon (dalam bentuk gas). Golongan mud volcano inilah yang merupakan mud volcano yang sesungguhnya.

Mud volcano juga banyak terjadi di Wilayah Indonesia bagian Timur khususnya Pulau Timor yang lebih di kenal dengan istilah Poton/ Poto. Berbeda dengan fenomena lumpur vulkanik yang biasanya terjadi, mud volcano (Poto/Poton) di pulau Timor merupakan aliran lumpur vulkanik bersuhu dingin dan tidak beraroma yang khas. Semburan lumpur yang terjadi mengalir secara pelahan berupa lumpur dingin bercampur air dan membentuk gunung lumpur dengan ketinggian berkisar 1- 3 meter.

Angle of repose merupakan sudut menurun tercuram dari sebuah tumpukan bahan relatif terhadap bidang horizontal bahan. Angle of repose berada diantara 0 dan 90 derajat walaupun sudut yang besar jarang terjadi, kecuali material yang berbatu. Perhitungan sudut tenang ini dilakukan untuk mengetahui besarnya sudut henti yang dibentuk oleh gunung lumpur vulkanik dengan ketinggian tertentu menggunakan metode trigonometri dan pengukuran sudut langsung dengan menggunakan alat ukur sudut (mista busur).

Perhitungan sudut tenang dengan metode trigonometri dilakukan dengan menggunakan rumus (1) dibawah ini:

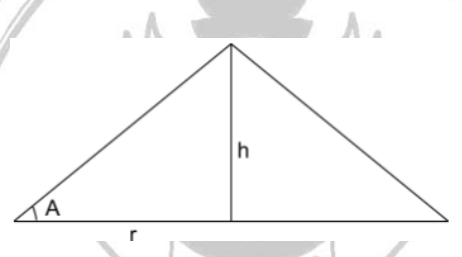

Gambar 1. Pengukuran angle of repose menggunakan alat ukur panjang (meteran/mistar)

$$
A=\operatorname{Tan}^{-1}(h / r)
$$

dengan :

\section{METODOLOGI PENELITIAN}

Penelitian ini menggunakan metode kepustakaan dan pengumpulan data secara primer dan sekunder. Studi kepustakaan dilakukan dengan mengumpulkan data atau informasi dari literature maupun peneliti terdahulu mengenai mud volcano Desa Napan yaitu berupa data laboratorium dari studi terdahulu. Data primer diperoleh menggunakan teknik sampling dan pengujian laboratorium.

Data Pengujian laboratorium untuk memperoleh data angle of repose merupakan pengujian lanjutan dari data-data terpublikasi terdahulu yang meliputi pengujian kadar air, gradasi butiran, batas atterberg, dan pengujian parameter reologi oleh Naikofi, dkk. (2017). Sedangkan data sekunder dilakukan melalui pengamatan langsung mengenai proses semburan lumpur, bentuk dan aliran lumpur riil yang terjadi. 


\section{HASIL DAN PEMBAHASAN}

Tahapan pengujian menggunakan data terpublikasi sebelumnya oleh Naikofi, dkk. (2017) yaitu data kadar air (w), berat isi tanah $(\gamma)$, berat jenis tanah (Gs), Batas-batas Aterberg (liquid limit, LL dan Plastic Limit, PL). Hasil Pengujian laboratorium menunjukkan bahwa klasifikasi jenis tanah tersebut tergolong tanah lempung anorganik dengan plastisitas rendah. Tanah dengan plastisitas rendah adalah tanah yang menunjukkan kencendrungan untuk mencair akibat perubahan kadar air yang meningkat. Data hasil publikasi terkait lumpur vulkanik Napan ditampilkan dalam berikut :

Tabel 1. Data hasil pengujian atterber limit (Naikofi dkk., 2017)

\begin{tabular}{|c|c|c|c|c|c|}
\hline Sampel & Soil & Gs & LL & PL & PI \\
\hline A & Napan & 2.78 & 20.30 & 19.35 & 1.05 \\
\hline
\end{tabular}

Pengujian sudut henti/angle of repose dilakukan dengan persentase kadar air pada kondisi viscous liquit menggunakan data terpublikasi yaitu pada kadar air $27.80 \%$, Perhitungan angle of repose menggunakan metode trigonometri seperti pada Gambar 1 dan rumus (1). Sedangkan kondis pengujian sampel di laboratorium, ditunjukkan pada Gambar 2 berikut:

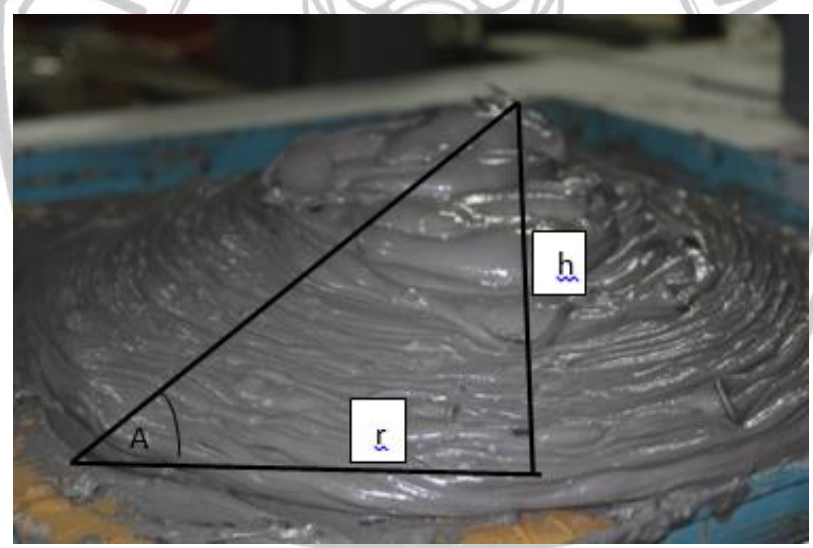

Gambar 2. Kondisi material pengujian angle of repose di Laboratorium

Hasil pengujian angle of repose pada lumpur vulkanik Napan diperoleh kurva hubungan antara Angle of Repose dan Kadar air seperti pada Tabel 2.

Tabel 2. hasil pengujian angle of repose

\begin{tabular}{|c|c|c|c|c|}
\hline LI & w (\%) & $\mathrm{h}(\mathrm{cm})$ & $\mathrm{r}(\mathrm{cm})$ & $\begin{array}{c}\mathrm{A}=\text { Tan-1 (h/r) } \\
\text { derajat }\left({ }^{(}\right)\end{array}$ \\
\hline 0.8 & 25.69 & 12.2 & 13.5 & 42.10 \\
\hline 0.9 & 26.75 & 11.3 & 14.5 & 37.93 \\
\hline 1 & 27.55 & 9.2 & 16.8 & 28.71 \\
\hline 1.1 & 28.73 & 8.5 & 18 & 25.28 \\
\hline 1.2 & 29.70 & 8 & 20.5 & 21.32 \\
\hline
\end{tabular}


Hubungan antara kadar air dengan Anggel of Repose ditampilkan dalam garfik pada Gambar 3. Grafik (Gambar 3) menunjukkan bahwa sudut tenang berbanding terbalik dengan kadar air, dimana kadar air semakin tinggi, maka angel of repose akan semakin rendah. Sebaliknya apabila angel of repose semakin tinggi, maka kadar air akan semakin rendah.

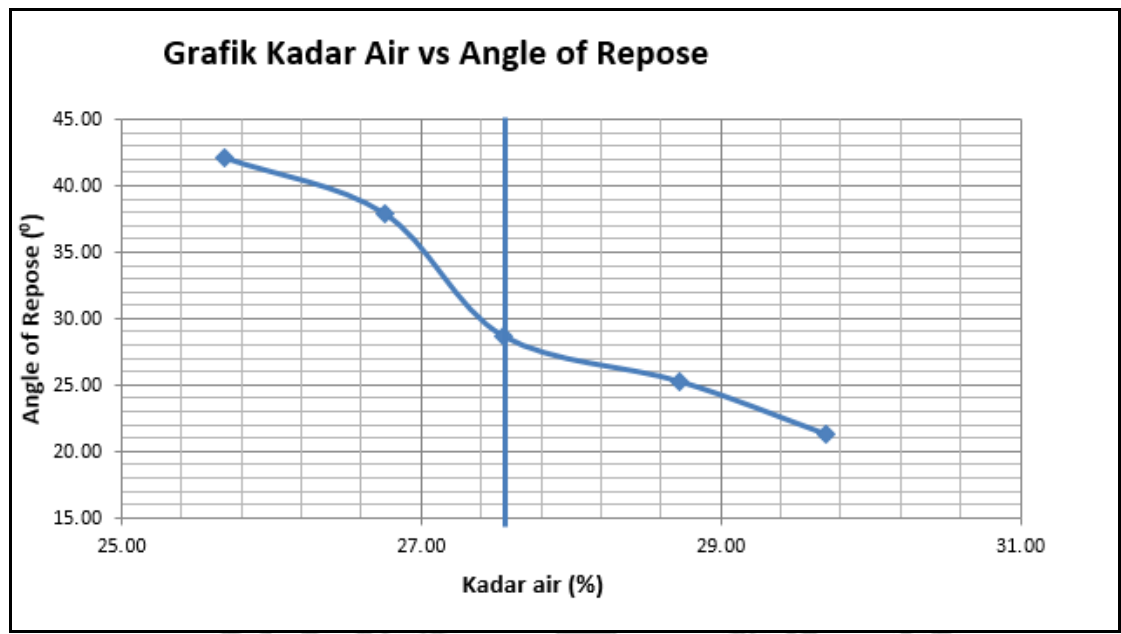

Gambar 3. Kurva hubungan antara kadar air dan angle of repose

Hasil pengujian sudut henti yang didasarkan pada jumlah kadar air pada kondisi viscous liquid dimana LI sama dengan 1.00 pada saat kadar air sama dengan $27.80 \%$ diperoleh angle of repose sebesar $28.71^{\circ}$.

\section{KESIMPULAN}

Lumpur vulkanik Napan tergolong dalam material lempung anorganik dengan memiliki nilai indeks plastisitas yang rendah dan didominasi oleh material kuarsa dan mineral lempung yang memiliki sifat relatif stabil (kembang-susut rendah), kristalnya tidak saling tarik menarik, plastisitasnya rendah. Angle of repose yang terbetuk pada saat kondisi viscous liquid yaitu pada kadar air $27.80 \%$ adalah sebesar $28.71^{0}$.

\section{DAFTAR PUSTAKA}

B. Widjaja dan Pratama, T. I. "Pengaruh Kemiringan Bidang Gelincir dan Indeks Kecairan Terhadap Penentuan Nilai Viskositas Menggunakan Flume Chanel. Seminar Nasional Teknik Sipil XI. ISBN:978-602-72056-0-4, Bidang Geoteknik, 2015, pp. 729-801.

B. Widjaja dan Lee, S.H.H. "Indikator Batas Cair Terhadap Bahaya Longsoran Tanah," Seminar Konferensi Nasional Teknik Sipil 7 (KoNTeks 7), Universitas sebelas Maret (UNS)-Surakarta, 24-26 Oktober 2013.

B. Widjaja, P.P. Rahardjo, A.R. Putri, D.W. Setiabudi, dan I. Octora, Perbandingan Yield Stress dan Viskositas menggunakan Vane Shear Test dan Flow Box Test untuk Menjelaskan Perilaku Mudflow". LPPM Universitas Katolik Parahyangan, Perjanjian No: III/LPPM/2014. Bandung 2014. 
Dinas PU Propinsi NTT., "Laporan Tinjauan Geologi Mud Volcano Embung Samaliang Semau," Dinas Pekerjaan Umum Propinsi NTT, Kupang,2015.

M. I. R. Naikofi, B. Widjaja, dan P.P. Rahardjo, Studi Reologi Mud Volcano Di Desa Napan Pulau Timor Dengan Flow Box Test. Seminar National Conference of Civil Engineering $1^{\text {st }}$, Institut Teknologi Kalimantan, Balikpapan, 4 Mei, 2017. pp. 7378.

N. Herawati "Analisis Risiko Lingkungan Aliran Air Lumpur Lapindo ke Badan Air," Tesis. Universitas Diponegoro. 2006.

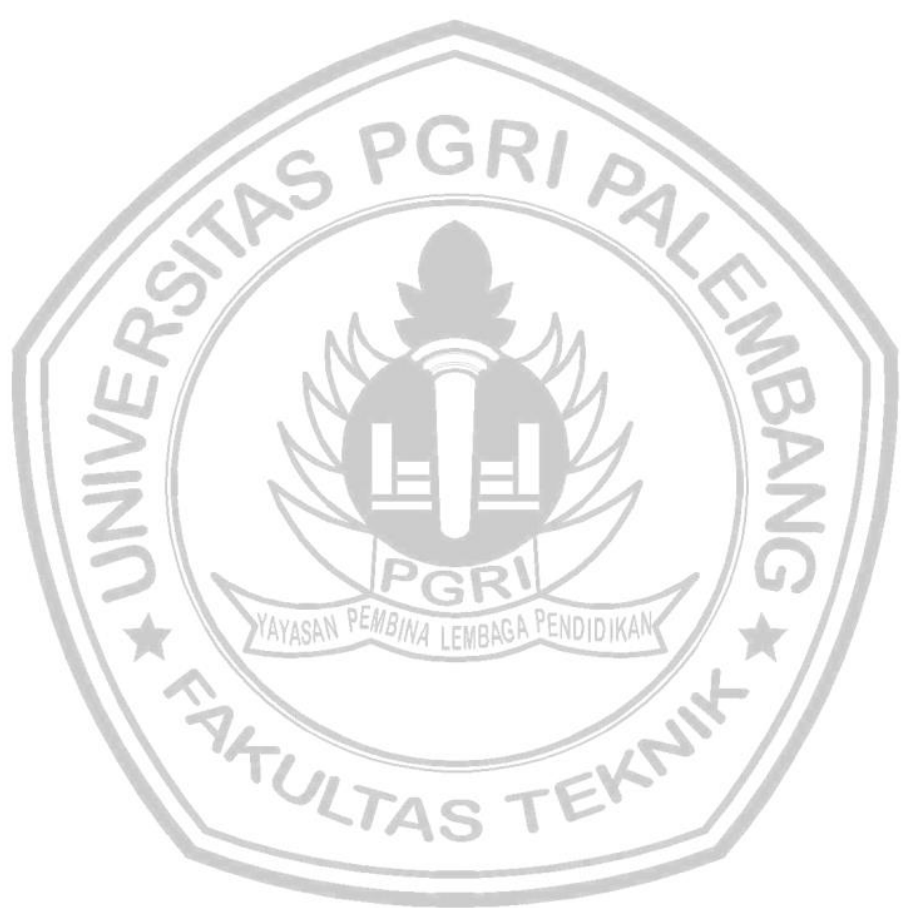

